\title{
Shining a Hot Light on Emerging Photoabsorber Materials: The Power of Rapid Radiative Heating in Developing Oxide Thin-film Photoelectrodes
}

Ronen Gottesman, ${ }^{\text {,* }}$ Isabella Peracchi, ${ }^{\mathrm{a}, \mathrm{b}}$ Jason L. Gerke, ${ }^{\mathrm{a}, \mathrm{b}}$ Rowshanak Irani, ${ }^{\mathrm{a}}$ Fatwa F. Abdi, ${ }^{\mathrm{a}}$ and Roel van de $\mathrm{Krol}^{\mathrm{a}, \mathrm{b}}$

a.Institute for Solar Fuels, Helmholtz-Zentrum Berlin für Materialien und Energie GmbH, Hahn-MeitnerPlatz 1, 14109 Berlin, Germany.

${ }^{\mathrm{b}}$ Institut für Chemie, Technische Universität Berlin, Straße des 17. Juni 124, 10623 Berlin, Germany. ronen.gottesman@helmholtz-berlin.de; roel.vandekrol@helmholtz-berlin.de

\section{Experimental Section}

Films Deposition: all films were deposited using a PLD system (PREVAC, Poland) by ablating with a KrF-Excimer laser (248 nm, LPXPro 210, COHERENT) commercial targets $\left(\mathrm{SnWO}_{4}, 99.99 \%\right.$, METALLIC FLEX, $\mathrm{Ta}_{2} \mathrm{O}_{5}, \mathrm{TiO}_{2}$ and $\mathrm{WO}_{3}, 99.99 \%$, FHR, Ni 99.99\%, Alfa Aesar). The target-to-substrate distance was $60 \mathrm{~mm}$, and all substrates were FTO-coated glass (TEC 7, Pilkington), cleaned in a 1 vol \% Triton solution (Triton X-100, Sigma-Aldrich), deionized water, and ethanol (Sigma-Aldrich) for $10 \mathrm{~min}$ in each solution. Table S1 shows the PLD and RTP conditions for each material.

Table S1. Summary of the PLD and RTP parameters and conditions used in the study.

\begin{tabular}{|c|c|c|c|c|c|c|}
\hline $\begin{array}{l}\text { Target } \\
\text { Material }\end{array}$ & $\begin{array}{l}\text { Laser } \\
\text { fluence }\end{array}$ & $\begin{array}{l}\text { PLD } \\
\text { Substrate } \\
\text { temperature }\end{array}$ & $\begin{array}{l}\text { PLD } \\
\text { Background } \\
\text { pressure }\end{array}$ & $\begin{array}{l}\text { RTP } \\
\text { environment } \\
(1 \mathrm{~atm})\end{array}$ & $\begin{array}{l}\text { RTP } \\
\text { temperature }\end{array}$ & Dwell time \\
\hline$\alpha-\mathrm{SnWO}_{4}$ & $2 \mathrm{~J} / \mathrm{cm}^{2}$ & $\begin{array}{l}\text { Room } \\
\text { temperature }\end{array}$ & $\begin{array}{l}1 \times 10^{-4} \\
\text { millibar }\end{array}$ & $\mathrm{Ar}$ & $550{ }^{\circ} \mathrm{C}$ & $1-8 \min$ \\
\hline $\mathrm{Ni}$ & $2 \mathrm{~J} / \mathrm{cm}^{2}$ & $\begin{array}{l}\text { Room } \\
\text { temperature }\end{array}$ & $\begin{array}{l}1 \times 10^{-2} \\
\text { millibar }\end{array}$ & N/A & N/A & N/A \\
\hline $\mathrm{Ta}_{2} \mathrm{O}_{5}$ & $2.5 \mathrm{~J} / \mathrm{cm}^{2}$ & $500{ }^{\circ} \mathrm{C}$ & $\begin{array}{l}1 \times 10^{-6} \\
\text { millibar }\end{array}$ & $\mathrm{O}_{2} / \mathrm{Ar} / \mathrm{N}_{2}$ & $850{ }^{\circ} \mathrm{C}$ & $<5 \mathrm{sec}$ \\
\hline $\mathrm{TiO}_{2}$ & $2 \mathrm{~J} / \mathrm{cm}^{2}$ & $500{ }^{\circ} \mathrm{C}$ & $\begin{array}{l}1 \times 10^{-6} \\
\text { millibar }\end{array}$ & $\begin{array}{l}80: 20 \\
\text { mixture of } \\
\mathrm{N}_{2}: \mathrm{O}_{2}\end{array}$ & $850{ }^{\circ} \mathrm{C}$ & $<5 \mathrm{sec}$ \\
\hline
\end{tabular}




\begin{tabular}{|l|l|l|l|l|l|l|}
\hline $\mathrm{WO}_{3}$ & $2 \mathrm{~J} / \mathrm{cm}^{2}$ & $500{ }^{\circ} \mathrm{C}$ & $\begin{array}{l}1 \times 10^{-6} \\
\text { millibar }\end{array}$ & $\begin{array}{l}80: 20 \\
\text { mixture of } \\
\mathrm{N}_{2}: \mathrm{O}_{2}\end{array}$ & $850{ }^{\circ} \mathrm{C}$ & $<5 \mathrm{sec}$ \\
\hline
\end{tabular}

Furnace heating and rapid thermal processing: Conventional furnace heating of the binary oxides was performed at $500{ }^{\circ} \mathrm{C}$ in air at a heating rate of $10{ }^{\circ} \mathrm{C} / \mathrm{min}$. Rapid thermal processing (RTP) was conducted using a Rapid Thermal Processor (model: AS-One 100, ANNEALSYS). In a typical RTP procedure, a sample is placed on a $\mathrm{SiC}$ wafer, used as a susceptor, with an optical pyrometer monitoring the temperature of the SiC. Additionally, the surface temperatures of the samples were monitored by a thermocouple attached to the surface with an indium contact. The susceptor with the sample placed on top is slowly heated to $400{ }^{\circ} \mathrm{C}($ rate $=1 \mathrm{~K} / \mathrm{sec})$ and then maintained at that temperature for 5 minutes. Next, the temperature is rapidly increased to the desired process temperature. In the case of $\mathrm{SnWO}_{4}$, the desired temperature was $550{ }^{\circ} \mathrm{C}$ (rate $=10 \mathrm{~K} / \mathrm{sec}$ ), which was maintained for 1 to 8 minutes. In the case of the binary oxides, the RTP was configured to shut off the illumination when the temperature reached $850{ }^{\circ} \mathrm{C}$. At the highest heating rates of $90 \mathrm{~K} / \mathrm{sec}$, the maximum temperature overshoots were $\sim 30{ }^{\circ} \mathrm{C}$, and the dwell time is defined as the length of time $\geq 850{ }^{\circ} \mathrm{C}$ (i.e., $\sim 850-880{ }^{\circ} \mathrm{C}$ ). The dwell time at each desired temperature appears in Table S1. In all cases, when illumination shuts off, the temperature decreases below $300{ }^{\circ} \mathrm{C}$ after $\sim 1 \mathrm{~min}$ and reaches room temperature after $\sim 10 \mathrm{~min}$.

Characterization: X-ray diffraction (XRD) measurements were performed using a Bruker D8 diffractometer with $\mathrm{Cu} \mathrm{K} \alpha$ radiation. Measurements were carried out in a grazing incidence geometry (angle of incidence was 2 degrees) with a step size of 0.04 degrees and a step duration of 6 sec. The data were normalized after removing the background without additional data averaging or noise reduction. Xray photoelectron spectroscopy (XPS) was performed with a SPECS PHOIBOS 100 analyzer at a base pressure of $\sim 10^{-10}$ mbar. Monochromatic Al Ka radiation $(\mathrm{hn}=1486.74 \mathrm{eV}$, SPECS FOCUS 500 
monochromator) was applied with the pass energy of 30 and $10 \mathrm{eV}$. The step sizes were chosen to be 0.5 $\mathrm{eV}$ for the survey and $0.05 \mathrm{eV}$ for the fine spectra. For fitting the peaks, XPSPEAK software with Voigt profiles and a Shirley background subtraction was applied. The adventitious carbon (C 1s) peak at a binding energy of $284.5 \mathrm{eV}$ was used for the calibration of binding energies.

UV-VIS measurements were performed using a PerkinElmer Lambda 950 spectrophotometer with an integrating sphere. Samples were placed inside the integrating sphere with an offset of $\sim 7.5^{\circ}$ from the incident light, and the transflectance TR (transmittance $\mathrm{T}+$ reflectance R) was measured. SEM imaging was carried out at a Zeiss UltraPlus scanning electron microscope operated at $12.5 \mathrm{kV}$ acceleration voltage. The grain sizes were quantified by using the ImageJ software.

Photoelectrochemical measurements were performed in the three-electrode configuration under the control of a potentiostat (EG\&G Princeton Applied Research 273A). The studied films were connected as the working electrode in a custom-designed PEC cell with a calibrated $\mathrm{Ag} / \mathrm{AgCl}$ reference electrode (XR300, Radiometer Analytical, $\mathrm{E}_{\mathrm{Ag} / \mathrm{AgCl}}=0.199 \mathrm{~V}$ vs. normal hydrogen electrode, NHE), and a platinum wire as the counter electrode. All the measured potentials were converted to the reversible hydrogen electrode (RHE) scale using the Nernst equation. The illuminated area of the sample was $0.28 \mathrm{~cm}^{2}$, which is identical to the area exposed to the electrolyte. The electrolyte used to measure the $\alpha-\mathrm{SnWO}_{4}$ was a 0.5 M potassium phosphate (KPi) buffer solution prepared by adjusting the ratio of $\mathrm{KH}_{2} \mathrm{PO}_{4}$ (99\%, SigmaAldrich) and $\mathrm{K}_{2} \mathrm{HPO}_{4}$ (99\%, Sigma-Aldrich) to obtain a pH 7 solution. $0.5 \mathrm{M} \mathrm{Na}_{2} \mathrm{SO}_{3}$ (99\%, SigmaAldrich) was added as a hole scavenger. Measurements of the binary oxides were performed in $0.1 \mathrm{M}$ boric acid $\left(\mathrm{H}_{3} \mathrm{BO}_{3}, 99.5 \%\right.$, Merck) at $\mathrm{pH}$ 9. A WACOM super solar simulator (Model WXS-50S-5H, class AAA) was used as the illumination source and calibrated to closely resemble the AM1.5 global spectrum at $100 \mathrm{~mW} \mathrm{~cm}^{-2}$. 
For incident photon-to-current efficiency (IPCE) measurements, a LOT (LSH302) lamp and Acton Research monochromator (SP2150) were used. The incident-photon-to-current conversion efficiency (IPCE) values were calculated as follows:

$$
\operatorname{IPCE}(\%)=\frac{J_{P}\left(m A \mathrm{~cm}^{-2}\right) * 1240(V \mathrm{~nm})}{P\left(\mathrm{~mW} \mathrm{cm^{-2 }}\right) * \lambda(\mathrm{nm})} * 100
$$

Where $J_{p}$ is the averaged photocurrent density, $P$ is the power density of the incident light, and $\lambda$ is the wavelength. The power density was calibrated through the electrolyte contained between two quartz windows for front-side illumination and through FTO glass for backside illumination. This means that the reported IPCE values are for the film itself and not for the entire photoanode / PEC cell assembly. Absorbed photon-to-current efficiency (APCE) values were calculated by dividing the IPCE through the absorptance of the measured photoelectrode:

$$
\operatorname{APCE}(\%)=\frac{I P C E(\%)}{\text { Absorptance }}
$$




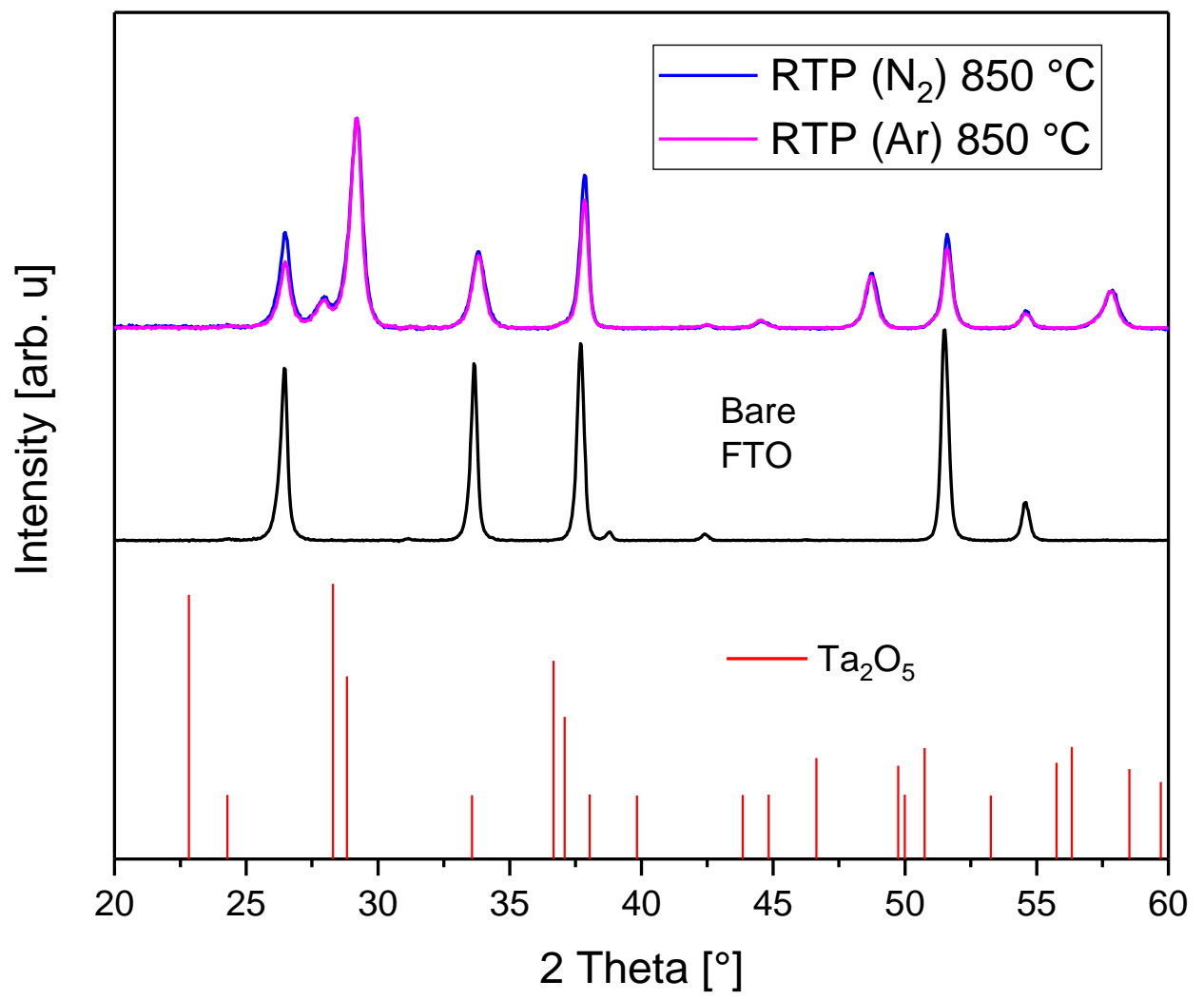

Figure S1. X-ray diffractograms of a bare FTO substrate, $\mathrm{Ta}_{\mathrm{x}} \mathrm{O}_{\mathrm{y}}$ on FTO: after RTP at $850{ }^{\circ} \mathrm{C}$ in $\mathrm{Ar}$ and $\mathrm{N}_{2}$ at a rate of $\sim 90{ }^{\circ} \mathrm{C} / \mathrm{sec}$. Ta $2 \mathrm{O}_{5}$ PDF: 01-082-9637. 


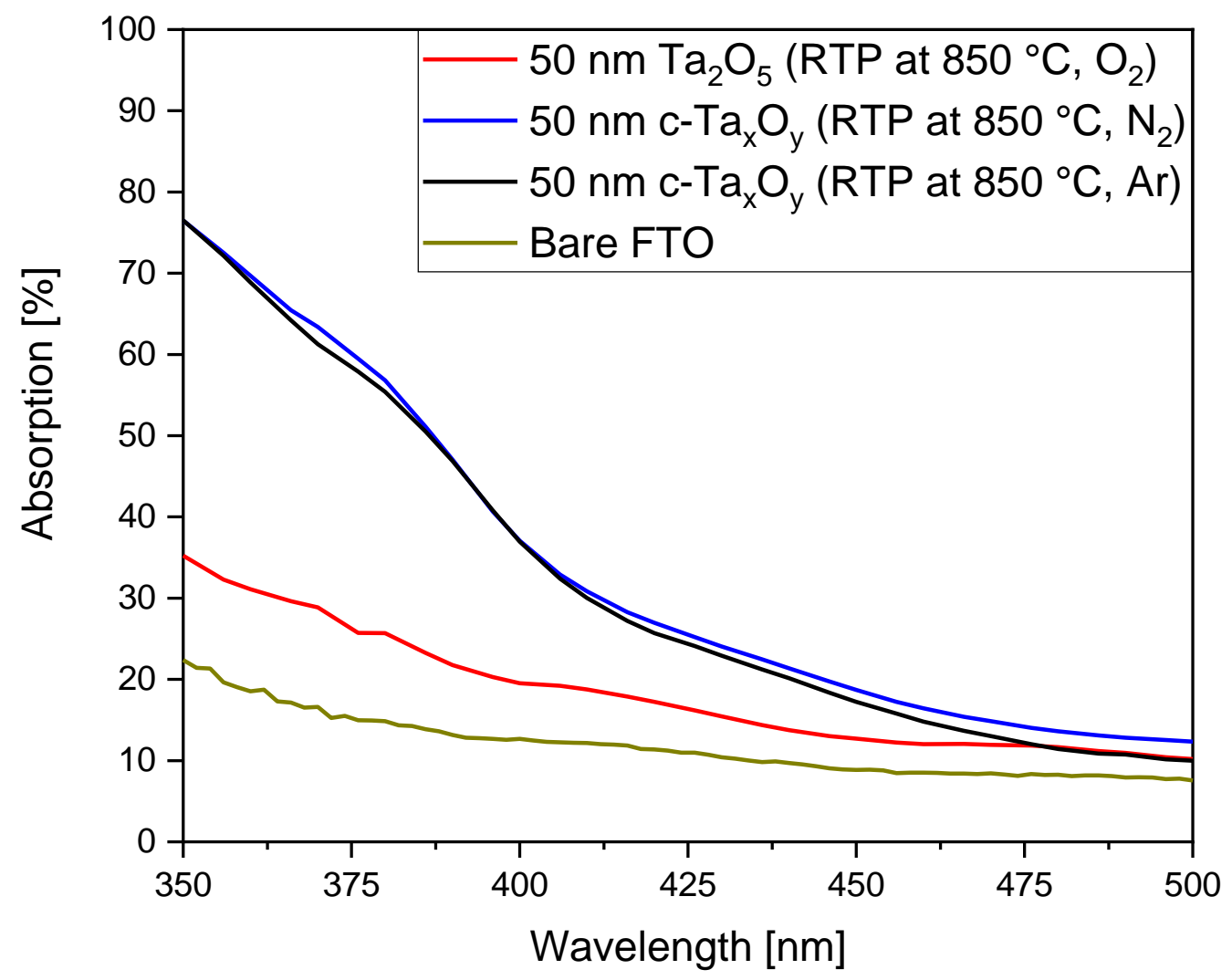

Figure S2. The absorption spectra of RTP-treated Tax $\mathrm{O}_{y}$ films under $\mathrm{O}_{2}, \mathrm{Ar}$, and $\mathrm{N}_{2}$. The spectrum of bare FTO is shown as a reference.
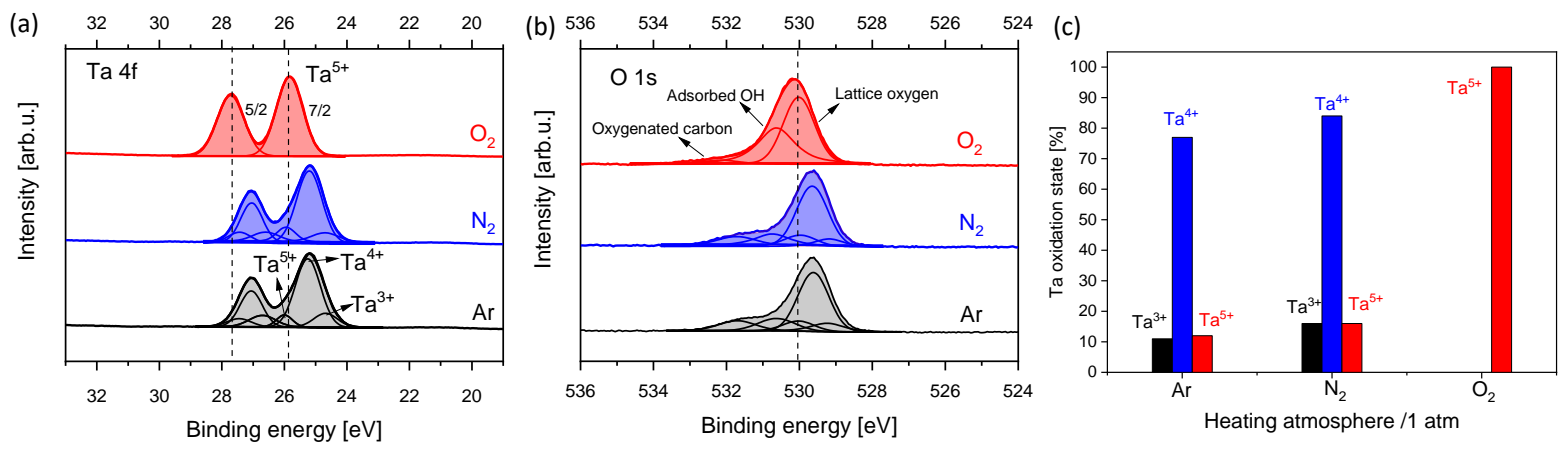

Figure S3. XPS spectra of a) Ta 4f, and b) O 1s core levels from top to bottom: RTP-treated $\mathrm{Ta}_{\mathrm{x}} \mathrm{O}_{\mathrm{y}}$ films under $\mathrm{O}_{2}, \mathrm{Ar}_{\text {, and }} \mathrm{N}_{2}$. Heating under $\mathrm{O}_{2}$ results with $\mathrm{Ta}_{2} \mathrm{O}_{5}$, whereas in the films heated under $\mathrm{N}_{2}$ and Ar multiple, lower oxidation states exist. C) Oxidation states quantities of Ta for each heating atmosphere. 


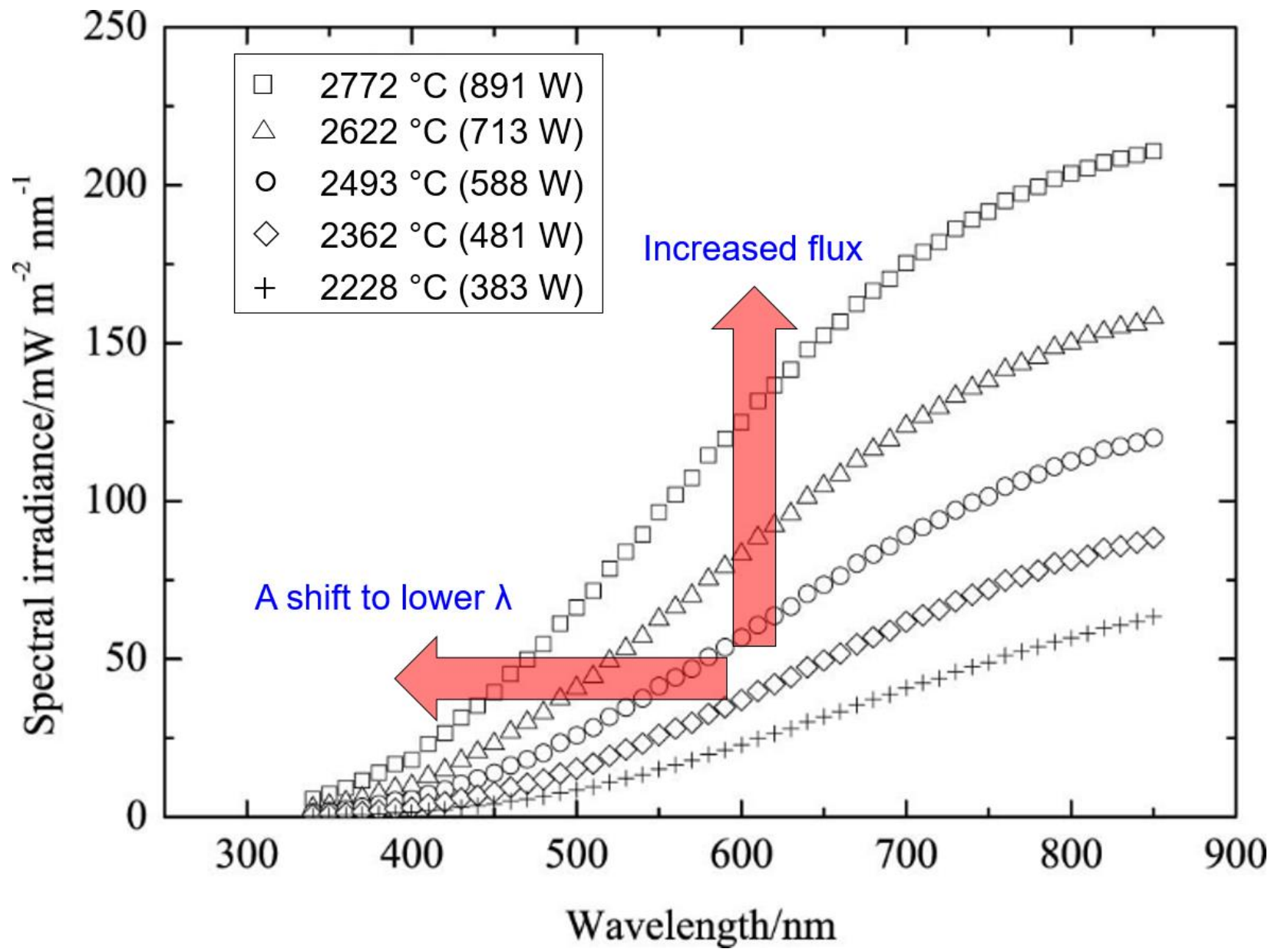

Figure S4. Measured spectral irradiances of a tungsten halogen lamp at different powers/temperatures. Modified from ref ${ }^{1}$.
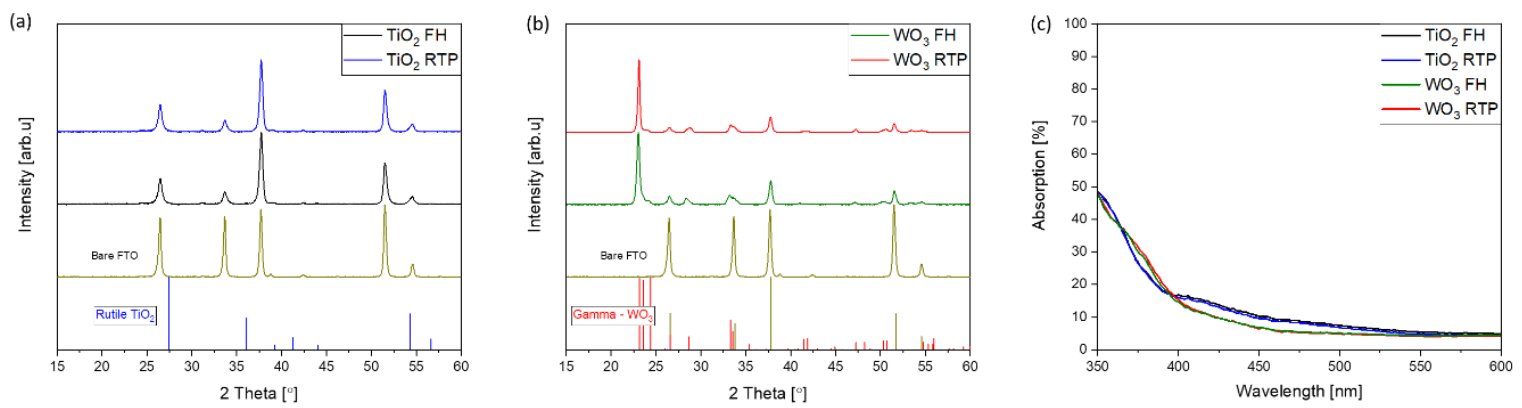

Figure S5. a, b) X-ray diffractograms of the $30 \mathrm{~nm} \mathrm{TiO}_{2}$ and $\mathrm{WO}_{3}$ photoelectrodes (and bare $\mathrm{FTO}$ as a reference), heated by $\mathrm{RTP}$ at $850{ }^{\circ} \mathrm{C}$ $\left(15^{\circ} \mathrm{C} / \mathrm{sec}\right.$, an $80: 20$ mixture of $\left.\mathrm{N}_{2}: \mathrm{O}_{2}\right)$ and $\mathrm{FH}$ at $500{ }^{\circ} \mathrm{C}$ (in air). c) The absorption spectra of all four photoelectrodes. 

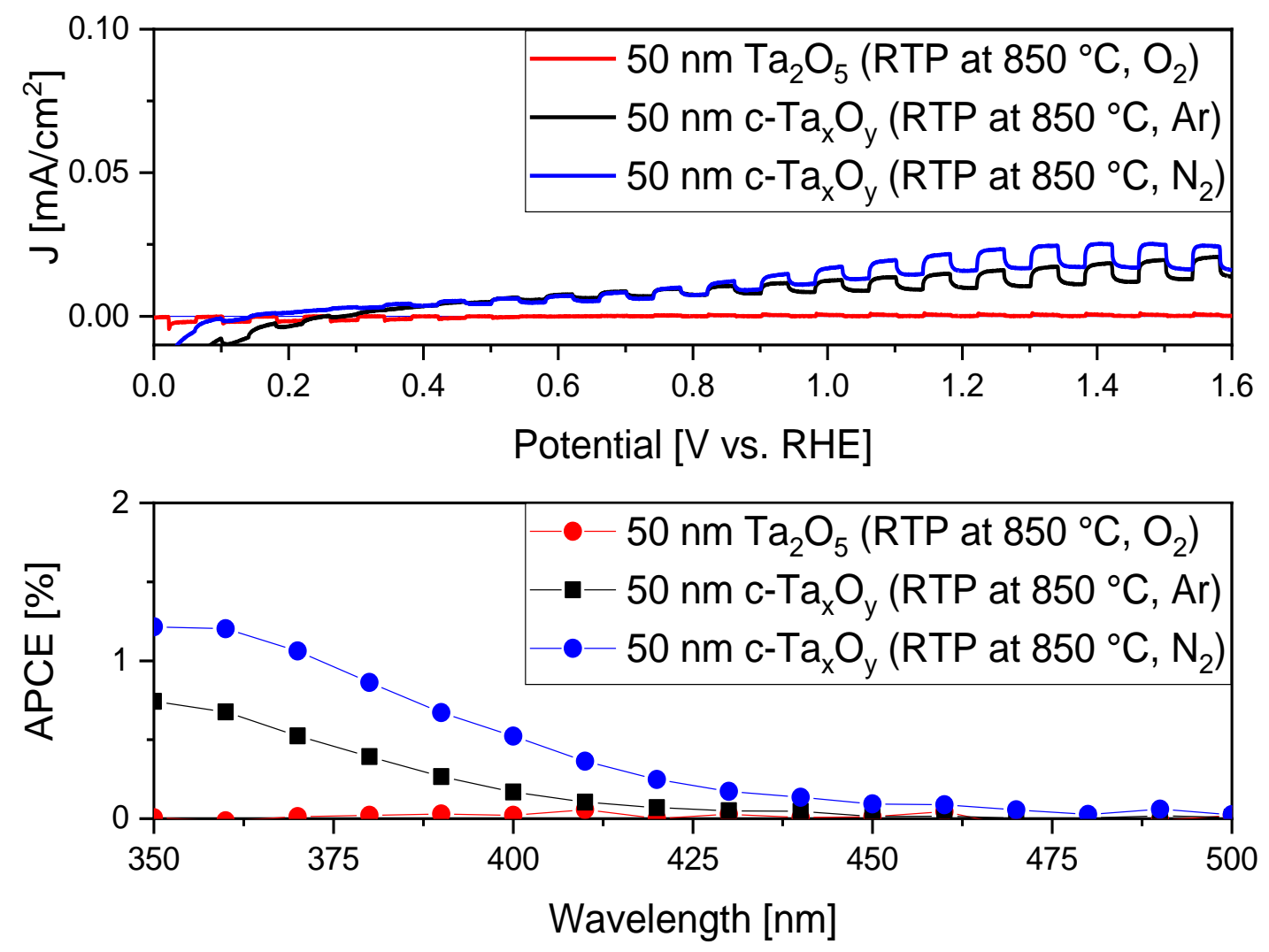

Figure S6. Chopped LSV scans and APCE spectra of RTP-treated $\mathrm{Ta}_{\mathrm{x}} \mathrm{O}_{\mathrm{y}}$ photoelectrodes under $\mathrm{O}_{2}$, Ar, and $\mathrm{N}_{2}$. The measurements were performed in $0.1 \mathrm{M}$ boric acid ( $\mathrm{pH}$ 9) under front-side illumination. These low photocurrents can result from one or more of the following factors: i) low specific surface area, ii) high bandgap energy that decreases the available light-harvesting range, iii) un-optimized films thickness, and iv) poor charge transport, which can lead to high recombination rates. A complete understanding of the carrier dynamics of these photoelectrodes and their structure cannot be resolved here is beyond the scope of this study. 


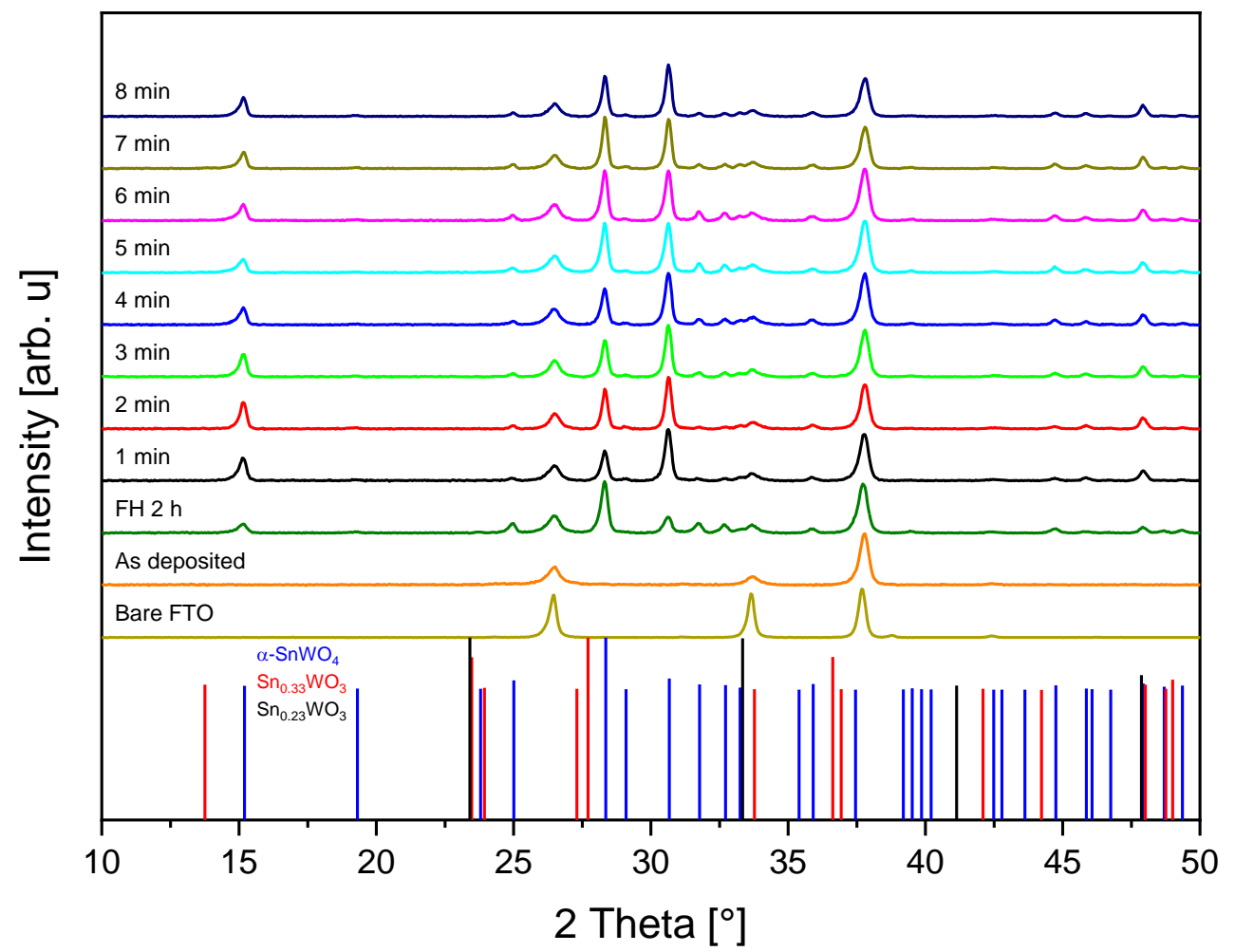

Figure S7. X-ray diffractograms of $1-8$ min RTP-treated and FH 2 h-treated $100 \mathrm{~nm} \alpha$-SnWO 4 photoelectrodes, shown on a shared baseline, with bare FTO as a reference. 

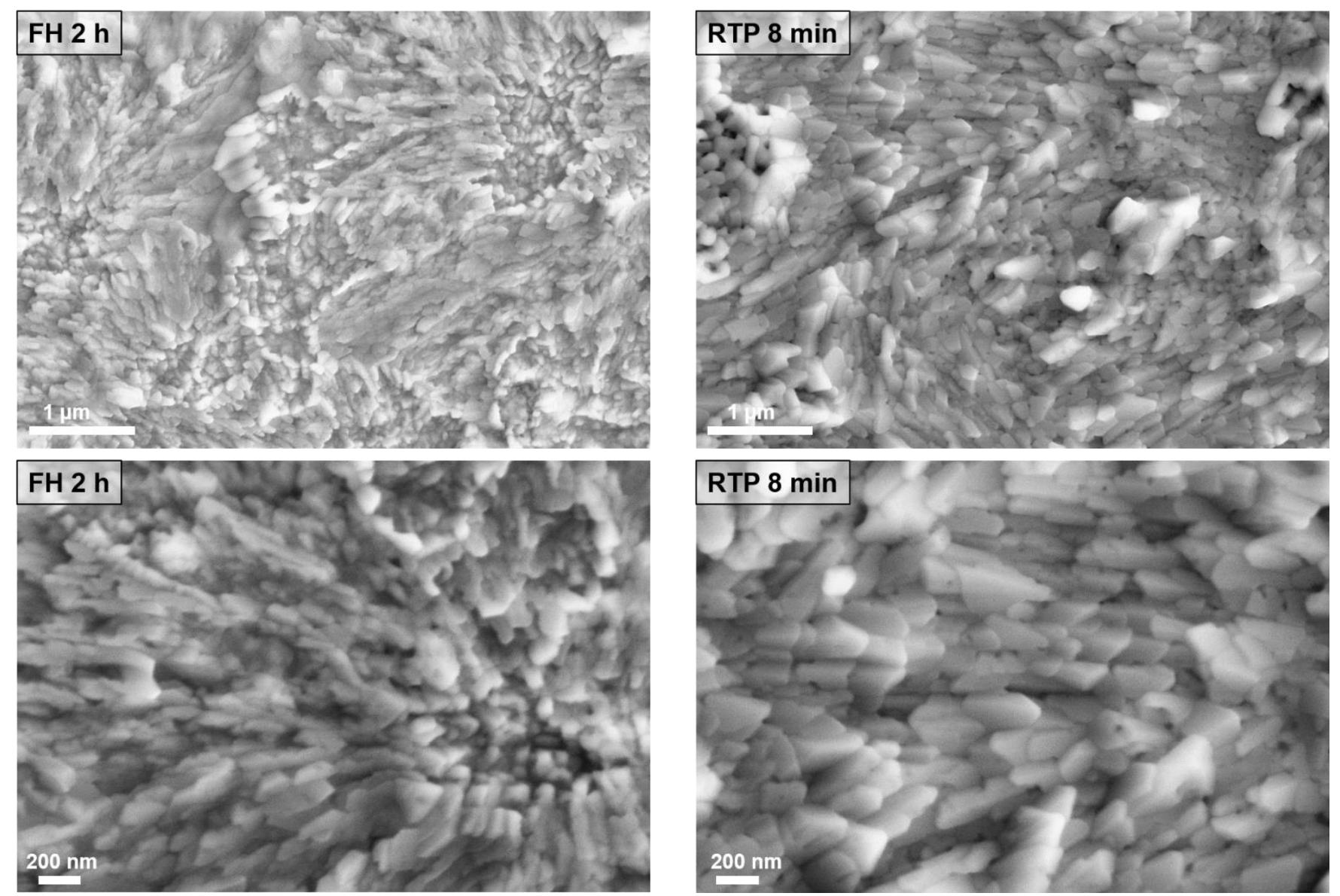

Figure S8. Top-view SEM images of $\alpha$-SnWO 4 photoelectrodes after heating by $\mathrm{FH}$ for $2 \mathrm{~h}$ at $550{ }^{\circ} \mathrm{C}$ in $\mathrm{Ar}$, and by RTP for 8 min at $550{ }^{\circ} \mathrm{C}$ in Ar. The average grain sizes (length and width) - FH: $233 \pm 89$ and $106 \pm 36 \mathrm{~nm}$, and RTP: $466 \pm 90$ and $172 \pm 43 \mathrm{~nm}$. 


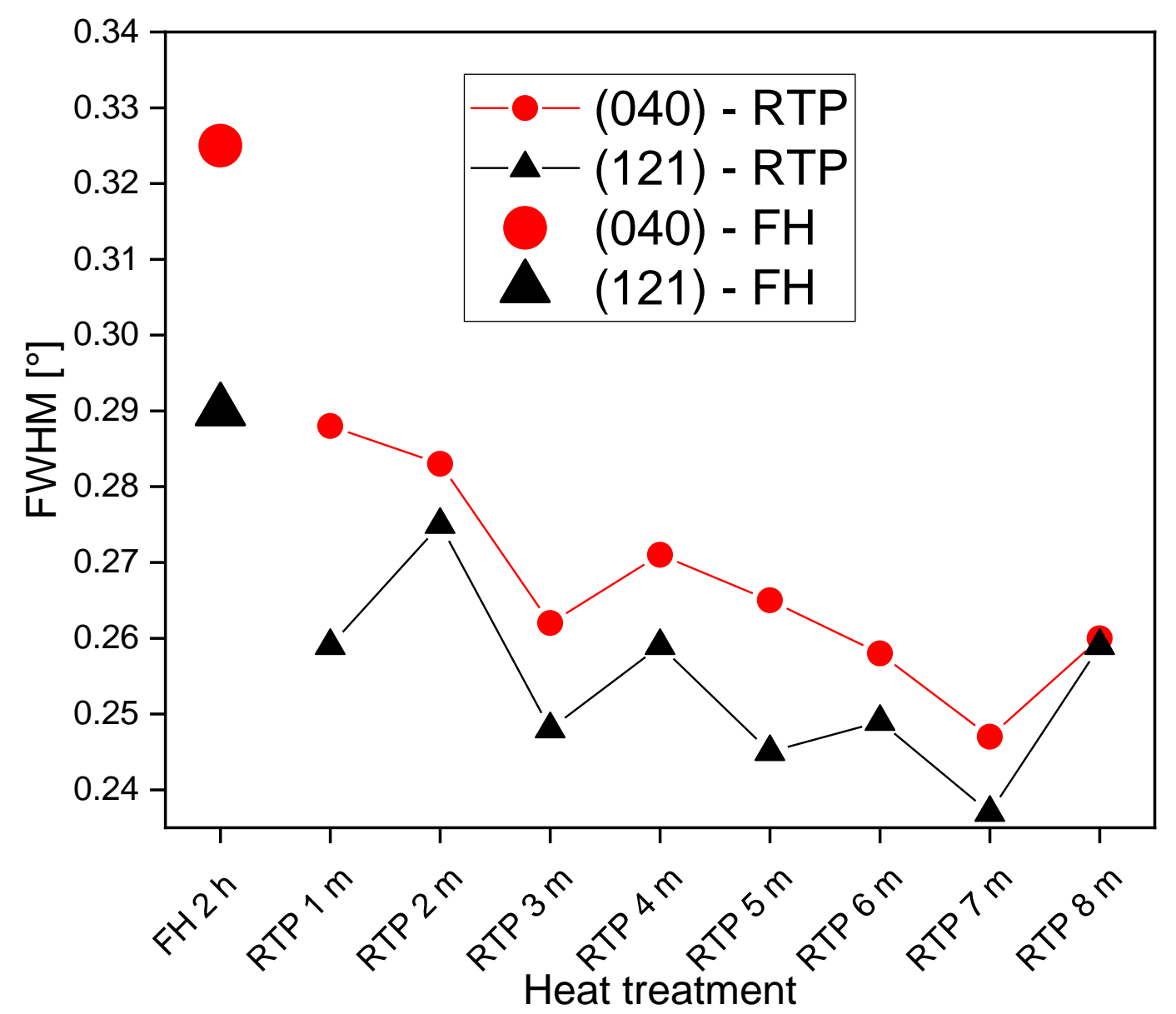

Figure S9. The FWHM of the (040) and (121) peaks plotted against the type and duration of heating treatment. 

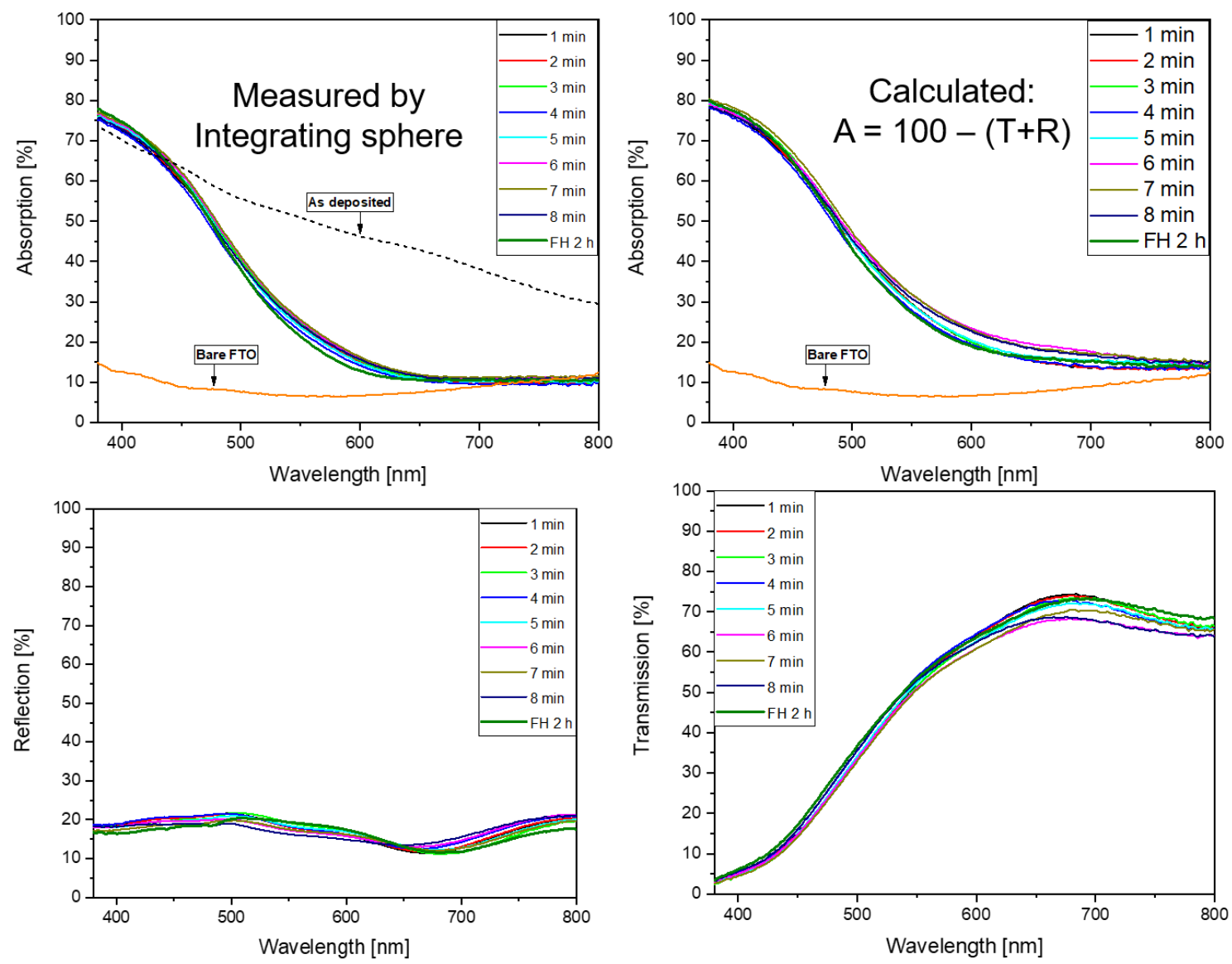

Figure S10. UV-VIS measurements of $\alpha-\mathrm{SnWO}_{4}$ films heated by both methods. Top: absorption plots, which were obtained by either measuring directly using an integrating sphere or by calculation by using the separately measured reflection and transmittance values that appear in the bottom plots.
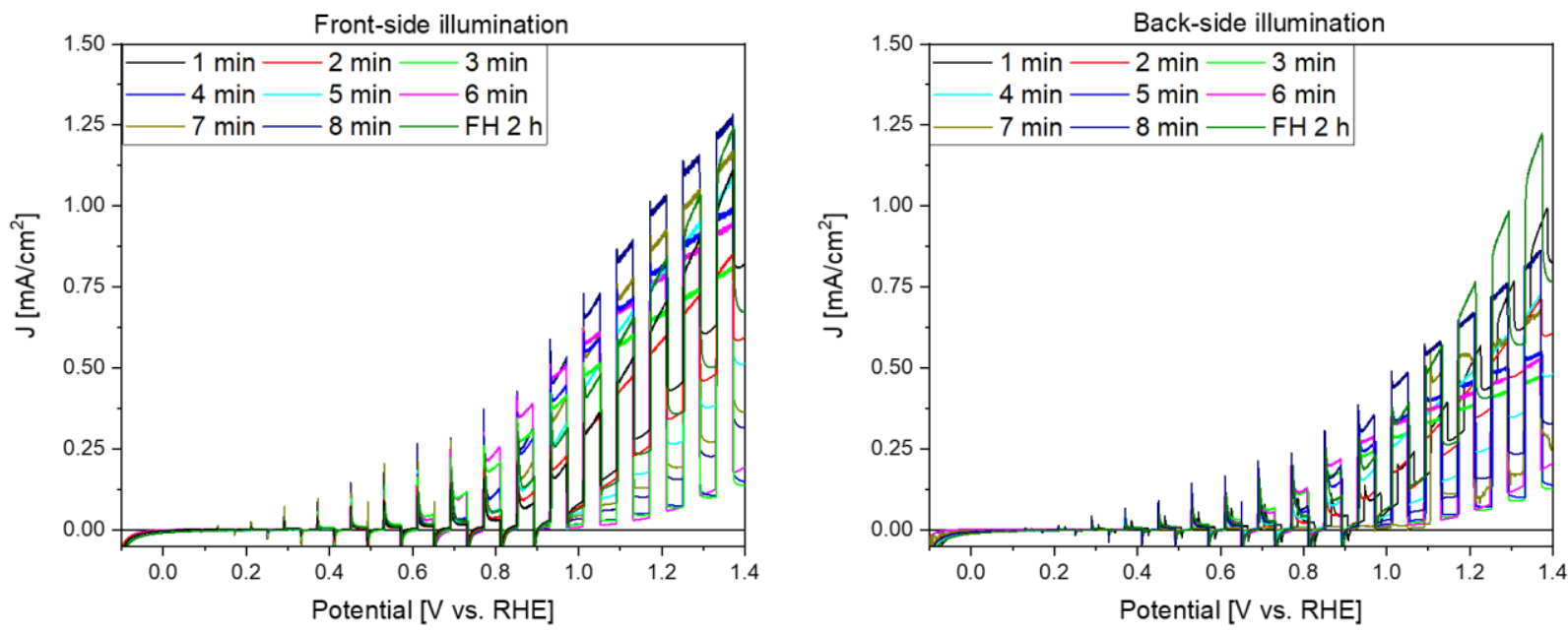

Figure S11. Chopped linear sweep voltammetry scans of the $1-8$ min RTP-treated and FH 2 h-treated $100 \mathrm{~nm} \alpha$-SnWO 4 photoelectrodes. 


\section{References:}

(1) Ojanen, M.; Kärhä, P.; Ikonen, E. Spectral Irradiance Model for Tungsten Halogen Lamps in 340-850nm Wavelength Range. Appl. Opt. 2010, 49 (5), 880-886. 